\title{
ANALISIS JUMLAH PENUMPANG KAPAL PENYEBERANGAN ULEE LHEUE TERHADAP PENERIMAAN RETRIBUSI PELAYANAN PELABUHAN KOTA BANDA ACEH
}

\author{
Muhammad Daud ${ }^{1)}$, Yushita Marini ${ }^{2)}$ \\ ${ }^{1)}$ Ilmu Administrasi Negara, Universitas Terbuka, Jl. Pendidikan/Bahagia, \\ email:mdaud@ecampus.ut.ac.id \\ ${ }^{2)}$ Ekonomi Akuntansi, Universitas Terbuka, Jl. Pendidikan/Bahagia, email: \\ yushita@ecampus.ut.ac.id
}

\begin{abstract}
Ulee Lheue Port is one of the ferry ports located in the city of Banda Aceh as a transportation to Sabang Weh Island. The city of Sabang is famous as one of the destinations of sharia tourism in Indonesia, therefore the revenue of the region can be obtained from the sea port service levy. As a source of revenue, the acceptance of port service levies is affected by the number of passengers on the ferry. This study aims to analyze whether there is an influence between the number of passenger ships crossing the acceptance of levy services sea port city of Banda Aceh. This research uses quantitative approach and data analysis used is simple regression analysis. The source of this research is taken from the Banda Aceh Statistics Data Report 2012 to 2015. The results show that there is influence between the number of passenger ship crossing to the receipt of levy service of seaport city of Banda Aceh.
\end{abstract}

Keywords : passenger ship crossing, sea port service levy

\begin{abstract}
Abstrak: Pelabuhan Ulee Lheue merupakan satu-satunya pelabuhan penyeberangan yang terdapat dikota Banda Aceh sebagai sarana transportasi ke Pulau Weh kota Sabang. Kota Sabang yang terkenal sebagai salah satu destinasi wisata syariah yang ada di Indonesia, karenanya pendapatan daerahnya dapat diperoleh dari retribusi pelayanan pelabuhan laut. Sebagai sumber penerimaan pendapatan asli daerah, penerimaan retribusi pelayanan pelabuhan dipengaruhi oleh jumlah penumpang kapal penyeberangan. Penelitian ini bertujuan untuk menganalisis apakah terdapat pengaruh antara jumlah penumpang kapal penyeberangan terhadap penerimaan retribusi pelayanan pelabuhan laut kota Banda Aceh. Penelitian ini menggunakan pendekatan kuantitatif dan analisis data yang digunakan adalah analisis regresi sederhana. Sumber penelitian ini diambil dari Laporan Data Statistik Banda Aceh tahun 2012 sampai dengan 2015. Hasil penelitian menunjukkan bahwa terdapat pengaruh antara jumlah penumpang kapal penyeberangan terhadap penerimaan retribusi pelayanan pelabuhan laut kota Banda Aceh.
\end{abstract}

\section{Kata kunci : Penumpang Kapal Penyeberangan, Retribusi Pelayanan Pelabuhan}

Provinsi Aceh merupakan provinsi terujung di Indonesia yang dalam penyelenggaraan pemerintahannya dengan memberikan kesempatan dan keleluasaan kepada Daerah untuk menyelenggarakan Otonomi Daerah. Kota Banda Aceh merupakan salah satu kota yang menerapkan Otonomi daerah yang berlandaskan undang-undang Nomor 32 Tahun 2004 tentang Pemerintah Daerah yang merupakan hak, wewenang dan kewajiban daerah otonom untuk mengatur dan mengurus sendiri urusan pemerintahan dan kepentingan masyarakat 
setempat sesuai dengan peraturan perundangundangan. Salah satu sumber keuangan daerah yang dimiliki dan dikelola oleh Pemerintah Daerah adalah Pendapatan Asli Daerah (PAD), merupakan pendapatan Daerah yang dipungut berdasarkan Peraturan Daerah sesuai dengan peraturan perundang-undangan. Pendapatan Asli Daerah bersumber dari Pajak Daerah, Retribusi Daerah, Hasil pengelolaan kekayaan Daerah yang dipisahkan dan lain-lain PAD yang sah. Semakin tinggi PAD maka semakin tinggi tingkat kemandirian dalam suatu daerah. Karenanya Pemerintah Daerah harus mengoptimalkan pengelolaan sumber pendapatan daerah yang berasal dari PAD.

Retribusi pelayanan pelabuhan laut merupakan salah satu sumber penerimaan yang potensial untuk dikembangkan sebagai salah satu sumber pendapatan daerah kota Banda Aceh. Untuk memperbesar pendapatan asli daerah maka pemerintah perlu menata dan menfasilitasi pelabuhan laut agar dapat memberikan sumbangan bagi pembangunan ekonomi. Menurut Oktaparizki (2016) Pelabuhan Ulee Lheue merupakan pelabuhan yang terdapat dikota Banda Aceh sebagai satu-satunya pelabuhan penyeberangan laut yang terhubung dengan pulau Weh, pulau terujung sebelah barat Indonesia. Kota sabang, sebagai salah satu kota destinasi pariwisata Indonesia yang terdapat di pulau Weh merupakan salah satu kota tujuan penyeberangan yang membawa para wisatawan dari pelabuhan Ulee Lheue. Karenanya sarana dan prasarana pelabuhan Ulee Lheue terus dikembangkan secara bertahap dari tahun 2015 -
2035.

Pelabuhan Ulee Lheue sendiri merupakan satu-satunya pelabuhan yang terdapat dikota Banda Aceh. Berbagai jenis kapal, baik itu kapal pengangkutan umum, pengangkutan barang maupun kapal penyeberangan dari dan ke kota Banda Aceh berdermaga dipelabuhan ini. Banyaknya wisatawan yang akan berwisata ke pulau Sabang yang melakukan perjalanan darat, akan melakukan penyeberangan melalui pelabuhan Ulee Lheue ini. Penghasilan dari jasa penyeberangan para penumpang kapal tersebut akan diperoleh dari para wisatawan yang akan menyeberang ke pulau Weh melalui pelabuhan Ulee Lheue. Karenanya pelabuhan ini merupakan penghasil pendapatan retribusi pelabuhan laut terbesar di kota Banda Aceh.

Sejalan dengan hal tersebut, sesuai dengan amanat UU No. 28 Tahun 2009 dalam pengelolaan pajak daerah, Pemerintah Kota Banda Aceh membuat Peraturan Daerah Nomor 6 Tahun 2012 Tentang Anggaran Pendapatan Dan Belanja Kota Banda Aceh Tahun Anggaran 2013, yang mengatur tentang penerimaan anggaran pendapatan asli daerah Banda Aceh dari berbagai sektor, termasuk sektor Retribusi Pelayanan Pelabuhan Laut Daerah. Kemudian pada Qanun kota Banda Aceh Nomor 14 tahun 2011 mengenai Peraturan Retribusi Pelayanan Kepelabuhan juga telah mengatur mengenai layanan jasa kepelabuhan, maka penulis tertarik untuk meneliti jumlah penumpang kapal penyeberangan Ulee Lheue terhadap penerimaan retribusi pelayanan pelabuhan laut karena diharapkan mampu memberikan kontribusi 
terhadap Pendapatan Asli Daerah (PAD) kota Banda Aceh. Sesuai latar belakang yang dikemukakan di atas maka penulis melakukan penelitian yang berjudul tentang "Analisis Jumlah Penumpang Kapal Penyeberangan Ulee Lheue terhadap Penerimaan Retribusi Pelayanan Pelabuhan kota Banda Aceh".

Tujuan penelitian yang diharapkan adalah untuk mengetahui apakah terdapat pengaruh jumlah penumpang kapal penyeberangan Ulee Lheue terhadap penerimaan retribusi pelayanan pelabuhan laut kota Banda Aceh. Manfaat yang bisa diambil dalam penelitian ini adalah : 1) Manfaat akademik dapat memberikan sumbangan pemikiran dan kajian teoritis mengenai pelabuhan dan retribusi pelayanan pelabuhan serta pendapatan asli daerah, 2) Manfaat praktis, dapat mengingatkan kembali pentingnya pendapatan retribusi pelayanan pelabuhan laut, 3) Bagi peneliti lainnya dapat dijadikan referensi untuk penelitian selanjutnya.

\section{KAJIAN PUSTAKA}

\section{a. Pengertian Retribusi Pelayanan Pelabuhan}

Menurut Pasal 1 Undang Undang nomor 28 Tahun 2009 tentang Pajak Daerah dan Retribusi Daerah, Definisi Retribusi Daerah adalah pungutan di daerah sebagai pembayaran atas jasa atau perizinan tertentu yang disediakan oleh pemerintah daerah untuk kepentingan orang pribadi atau badan tertentu. Subjek atau Wajib Retribusi adalah orang pribadi atau badan yang terlibat atas pembayaran terhadap penggunaan jasa atau perizinan dari pemerintah daerah tersebut, termasuk pemungut atau pemotong retribusi daerah. Retribusi daerah nantinya akan menjadi penerimaan Pendapatan Asli Daerah (PAD) yang termasuk ke dalam Anggaran Pendapatan dan Belanja Daerah (APBD).

Sejalan dengan hal itu, Pemerintah Kota Banda Aceh membuat Peraturan Daerah Nomor 6 Tahun 2012 Tentang Anggaran Pendapatan Dan Belanja Kota Banda Aceh Tahun Anggaran 2013, yang mengatur tentang penerimaan anggaran pendapatan asli daerah Banda Aceh dari berbagai sektor, antara lain berasal dari : 1) Pajak daerah, 2) Retribusi daerah, 3) Hasil pengelolaan kekayaan daerah yang dipisahkan, 4) Lain-lain PAD yang sah meliputi hasil penjualan kekayaan daerah yang tidak dipisahkan, jasa giro, pendapatan bunga, keuntungan selisih tukar rupiah terhadap mata uang asing, dan komisi, potongan, atau bentuk lain dari penjualan, pengadaan barang dan/atau jasa oleh daerah.

Menurut Qanun kota Banda Aceh Nomor 14 tahun 2011 tentang Retribusi Pelayanan Kepelabuhan menyatakan bahwa Retribusi Pelayanan Kepelabuhan merupakan retribusi yang dipungut atas pelayanan jasa kepelabuhan, termasuk fasilitas lainnya dilingkungan pelabuhan yang disediakan, dimiliki, dan/ atau dikelola oleh Pemerintah kota. Objeknya adalah pelayanan jasa kepelabuhan yang diberikan, salah satunya meliputi jasa pelayanan terminal penumpang dan penggunaan dermaga. Subjek retribusi adalah orang pribadi atau badan yang menikmati atau menggunakan pelayanan jasa kepelabuhan. 
Dari definisi di atas dapat disimpulkan bahwa Retribusi Pelayanan Pelabuhan adalah Pendapatan yang diperoleh dari pungutan pengguna jasa kepelabuhan yang disediakan, dimiliki dan/atau dikelola oleh pemerintah daerah atau kota. Retribusi Pelayanan Labuhan tersebut kemudian akan menjadi Penerimaan Pendapatan Asli Daerah (PAD) yang termasuk ke dalam Anggaran Pendapatan dan Belanja Daerah (APBD).

\section{b. Pengertian Penumpang Kapal \\ Penyeberangan}

Menurut Peraturan Direktur Jenderal Perhubungan Darat No. AP.005/6/14/ DRJD/2011 menyatakan bahwa Angkutan Penyeberangan adalah angkutan yang berfungsi sebagai jembatan yang menghubungkan menghubungkan jaringan jalan dan/atau jaringan jalur kereta api yang dipisahkan oleh perairan untuk mengangkut penumpang dan kendaraan beserta muatannya, salah satunya adalah kapal ferry. Penumpang adalah orang yang menggunakan jasa angkutan penyeberangan termasuk awak kendaraan. Tempat yang dipergunakan sebagai kapal bersandar naik turun penumpang, dan/atau bongkar muat barang, berupa terminal dan tempat berlabuh kapal yang dilengkapi dengan fasilitas keselamatan dan keamanan pelayaran dan kegiatan penunjang pelabuhan serta sebagai tempat perpindahan intra-dan antarmoda transportasi disebut Pelabuhan.

Dari defenisi diatas dapat disimpulkan bahwa penumpang kapal penyeberangan adalah orang yang menggunakan jasa angkutan penyeberangan, dalam hal ini kapal penyeberangan yang naik atau turun kapal dipelabuhan

\section{c. Hubungan Penumpang Kapal Penyeberangan terhadap Retribusi Pelayanan Pelabuhan}

Menurut Pasal 1 Undang Undang nomor 28 Tahun 2009, retribusi pelayanan pelabuhan merupakan pungutan daerah sebagai pembayaran atas jasa pelayanan kepelabuhan, termasuk fasilitas lainnya di lingkungan pelabuhan yang disediakan, dimiliki, dan/atau dikelola oleh Pemerintah Daerah seperti kapal penyeberangan. Penumpang kapal penyeberangan merupakan pengguna jasa pelayanan kepelabuhan, sehingga disebut sebagai objek pajak retribusi.

Qanun kota Banda Aceh Nomor 14 tahun 2011 menyatakan bahwa wajib retribusi adalah setiap wajib pribadi atau perorangan, kenderaan dan kapal masuk dan menggunakan areal serta fasilitas pelabuhan dan/atau yang mendapat izin menggunakan tanah dan bangunan/ruangan diareal pelabuhan. Penumpang kapal penyeberangan yang menggunakan jasa pelabuhan untuk dapat naik atau turun kedalam angkutan penyeberangan dikenakan kewajiban membayar retribusi pelayanan pelabuhan sesuai dengan ketentuan peraturan masing-masing daerah. Angkutan penyeberangan laut dalam hal ini disebut kapal. Proses menurunkan penumpang dari kapal disebut debarkasi, sementara menaikkan penumpang dari kapal disebut embarkasi.

Dari banyaknya ketentuan perundangundangan dan ketentuan diatas, maka dapat 
disimpulkan bahwa Jumlah penumpang kapal penyeberangan memiliki hubungan terhadap pendapatan retribusi pelayanan pelabuhan dimana banyaknya jumlah penumpang akan meningkatkan pendapatan retribusi pelayanan pelabuhan.

Pelabuhan merupakan terminal transportasi laut yang kerap digunakan sebagai tempat persinggahan untuk menaikkan atau menurunkan penumpang transportasi laut. Bagi penumpang yang ingin melakukan perjalanan yang mengharuskan penyeberangan laut untuk sampai ketujuan, maka pelabuhan kerap diramaikan oleh para penumpang yang akan naik turun kapal penyeberangan yang akan bersandar didermaga pelabuhan tersebut.

Pelabuhan Ulee Lheue merupakan satusatunya pelabuhan yang berada diKota Banda Aceh sebagai terminal kapal penyeberangan yang akan menuju Kota Sabang. Kota Sabang yang merupakan salah satu kota wisata syariah kerap menjadi tujuan wisata kepulauan yang harus melalui transportasi laut dan udara. Karenanya Pelabuhan Ulee Lheue selalu diramaikan oleh wisatawan yang akan berkunjung menggunakan transportasi laut, sehingga jumlah penumpang kapal penyeberangan baik dari pengunjung dari para wisatawan maupun dari penduduk lokal akan dikenakan retribusi pelayanan pelabuhan oleh pemerintah daerah setempat. Sejalan dengan hal tersebut, maka secara sistematis dapat diuraikan sebagai berikut :

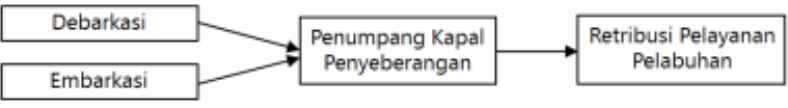

\section{Gambar 1 : Kerangka Pemikiran}

\section{METODE PENELITIAN}

\section{a. Jenis Penelitian}

Karena penelitian ini menggambarkan banyaknya penumpang kapal terhadap retribusi pelayanan, maka Penelitian ini menggunakan korelasi kuantitatif, yaitu menggambarkan suatu kondisi kedalam konteks kuantitatif yang direfleksikan kedalam variabel. Sesuai dengan pernyataan Fraenkel dan Wallen (2008) yang menyebutkan bahwa penelitian korelasi ke dalam penelitian deskripsi karena penelitian tersebut merupakan usaha menggambarkan kondisi yang sudah terjadi. Variabel penelitian ini adalah Jumlah Penumpang Kapal Penyeberangan dan Retribusi Pelayanan Pelabuhan.

\section{b. Populasi}

Sugiyono (2011) menyatakan bahwa populasi merupakan wilayah generalisasi yang terdiri atas: obyek/subyek yang mempunyai kualitas dan karakteristik tertentu yang ditetapkan oleh peneliti untuk dipelajari dan kemudian ditarik kesimpulannya. Maka populasi dalam penelitian ini adalah Jumlah Penumpang Kapal Penyeberangan dan Retribusi Pelayanan Pelabuhan Banda Aceh.

\section{c. Sampel}

Teknik pengambilan sampel dalam penelitian ini adalah purposive sampling (sampel yang bertujuan). Sampel yang digunakan dalam penelitian ini adalah Jumlah Penumpang Kapal Penyeberangan dan Jumlah Retribusi Pelayanan 
Pelabuhan Kota Banda Aceh tahun 2012 sampai dengan 2015.

\section{ANALISIS DATA}

\section{a. Analisis Regresi Sederhana}

Penelitian ini menganalisis hubungan regresi antara variabel independen $(\mathrm{X})$ dengan variabel dependen (Y). Metode analisis ini menghubungkan banyaknya jumlah Penumpang Kapal Penyeberangan setiap tahunnya dengan Jumlah Retribusi Pelayanan Pelabuhan Kota Banda Aceh. Menurut Sugiyono (2008) persamaan umum regresi linier sederhana adalah sebagai berikut :

$$
\mathrm{Y}=\mathrm{a}+\mathrm{bX}
$$

Keterangan :

$\mathrm{Y}=$ Retribusi Pelayanan Pelabuhan

$\mathrm{X}=$ Penumpang Kapal Penyeberangan

$\mathrm{a}=$ Konstan (nilai $\mathrm{Y}$ apabila $\mathrm{X}=0$ )

$\mathrm{b}=$ Koefisien regresi

Perhitungan penelitian ini diolah menggunakan aplikasi SPSS (Statistical Product and Service). Variabel-variabel dalam penelitian ini adalah Jumlah Penumpang Kapal Penyeberangan sebagai variabel independen $(\mathrm{X})$ dan Retribusi Pelayanan Pelabuhan sebagai variabel dependen $(\mathrm{Y})$ sebagai berikut :

- Variabel Independen : Jumlah Penumpang Kapal Penyeberangan (X), indikatornya jumlah debarkasi dan embarkasi penumpang kapal yang tercatat dalam Laporan Statistik Banda Aceh dari tahun 2012 sampai dengan 2015.

- Variabel Dependen : Retribusi Pelayanan Pelabuhan Laut (Y), Indikator Realisasi Pendapatan Retribusi Pelayanan Pelabuhan
Laut tahun 2012 sampai 2015.

\section{b. Uji Kualitas Data}

Uji kualitas data yang digunakan dengan menggunakan uji asumsi klasik sebagai pemenuhan asumsi-asumsi statistik yang harus dipenuhi dalam analisis regresi linear, antara lain uji heteroskedastisitas dan uji autokorelasi. Uji Normalitas data juga diperlukan untuk mengetahui apakah data yang diperoleh terdistribusi secara normal dan independen. Jika terdapat normalitas, maka residual akan terdistribusi secara normal dan independen, yaitu perbedaan antara nilai prediksi dengan skor yang sesungguhnya atau error akan terdistribusi secara simetris di sekitar nilai means sama dengan nol. (Sugiyono, 2008)

\section{c. Uji T}

Merupakan uji signifikansi yang berfungsi untuk mencari hubungan variabel X terhadap Y, maka hasil tersebut diuji dengan uji signifikansi dengan rumus yang digunakan menurut Sugiyono (2008) dalam menguji hipotesis (Uji t) adalah :

$$
\mathrm{t}_{\text {hitung }}=\frac{\mathrm{r} \sqrt{\mathrm{n}-2}}{\sqrt{1-\mathrm{r}^{2}}}
$$

$$
\begin{array}{ll}
\text { Keterangan : } \\
\text { thitung } & =\text { Nilai uji t } \\
\mathrm{r}^{2} & =\text { Koefisien Determinasi } \\
\mathrm{r} & =\text { Koefisien korelasi } \\
\mathrm{n} & =\text { Jumlah Sampel }
\end{array}
$$




\section{HASIL DAN PEMBAHASAN}

a. Jumlah

Penumpang

Kapal

\section{Penyeberangan}

Jumlah penumpang kapal penyeberangan yang terdata pada data statistik dari tahun 2012 sampai dengan tahun 2015 adalah sebagai berikut :

Tabel 1. Jumlah Penumpang Kapal Penyeberangan Ulee Lheue 2012 - 2015

\begin{tabular}{|c|c|c|c}
\hline Tahun & $\begin{array}{c}\text { Penumpang } \\
\text { Debarkasi }\end{array}$ & $\begin{array}{c}\text { Penumpang } \\
\text { Embarkasi }\end{array}$ & $\begin{array}{c}\text { Jumlah } \\
\text { Penumpang }\end{array}$ \\
\hline 2012 & 152.073 & 143.216 & 295.289 \\
\hline 2013 & 139.667 & 150.600 & 290.267 \\
\hline 2014 & 173.392 & 155.175 & 330.567 \\
\hline 2015 & 230.632 & 192.326 & 422.958 \\
\hline
\end{tabular}

Sumber : Badan Pusat Statistik Provinsi Aceh

Dari data tersebut, terlihat terjadinya peningkatan pada 4 (empat) tahun terakhir data Jumlah Penumpang Kapal Penyeberangan dari Pelabuhan Ulee Lheue.

\section{b. Retribusi Pelayanan Pelabuhan Kota}

\section{Banda Aceh}

Dengan banyaknya jumlah kunjungan wisatawan kekota Sabang, maka akan meningkat pula jumlah penumpang kapal penyeberangan yang berasal dari pelabuhan Ulee Lheue menuju kota Sabang. Sejalan dengan hal ini, maka kemungkinan besar akan meningkatkan pendapatan Retribusi Pelayanan Pelabuhan Kota Banda Aceh. Hal ini dapat dilihat dari besarnya Pendapatan Retribusi Pelayanan Pelabuhan Laut dimana setiap tahunnya mengalami peningkatan. Untuk mengetahui perkembangan Realisasi Pendapatan Retribusi Pelayanan Pelabuhan Kota Banda Aceh pada tahun 2012-2015 dapat dilihat dari tabel dibawah ini:
Tabel 2. Realisasi Pendapatan Retribusi Pelayanan Pelabuhan Laut Kota Banda Aceh Tahun 2012 - 2015

\begin{tabular}{|c|c|}
\hline Tahun & $\begin{array}{c}\text { Pendapatan Retribusi } \\
\text { Pelayanan Pelabuhan }\end{array}$ \\
\hline 2012 & 975.820 .125 \\
\hline 2013 & 1.026 .908 .210 \\
\hline 2014 & 1.102 .618 .175 \\
\hline 2015 & 1.509 .903 .550 \\
\hline Sumber : & $\begin{array}{c}\text { Badan Perencanaan Pembangunan } \\
\text { Daerah }\end{array}$ \\
\hline
\end{tabular}

Realisasi Pendapatan Retribusi Pelayanan Pelabuhan Laut Kota Banda Aceh setiap tahunnya terus meningkat, hal ini disebabkan Pelabuhan Ulee Lheue sebagai satu-satunya pelabuhan di Kota Banda Aceh merupakan pelabuhan yang banyak diminati oleh para wisatawan sebagai terminal sandar kapal penyeberangan menuju Pulau Weh atau kota Sabang.

\section{c. Pengaruh Jumlah Penumpang Kapal} Penyeberangan terhadap Pendapatan Retribusi Pelayanan Pelabuhan Kota

\section{Banda Aceh}

Kebanyakan pengguna pelayanan pelabuhan tersebut merupakan para wisatawan yang akan menumpang kapal penyebereangan menuju kota Sabang. Berdasarkan uji regresi linier sederhana dapat diketahui bahwa jumlah Penumpang Kapal Penyeberangan memiliki pengaruh terhadap Pendapatan Retribusi Pelayanan Pelabuhan Laut Kota Banda Aceh, seperti terlihat pada hasil analisis dibawah ini : 
Tabel 3. Tabel Regresi Linier

\begin{tabular}{|c|c|c|c|c|c|c|}
\hline \multicolumn{7}{|c|}{ ANOVA $^{a}$} \\
\hline Model & & Sum of Squares & df & Mean Square & $\mathrm{F}$ & Sig. \\
\hline \multirow[t]{3}{*}{1} & Regression & 177188001200000000 & 2 & 88594000610000000 & 4502.194 & $.011^{\mathrm{D}}$ \\
\hline & Residual & 19677961930000 & 1 & 19677961930000 & & \\
\hline & Total & 177207679200000000 & 3 & & & \\
\hline
\end{tabular}

Dari tabel 3 diperoleh nilai Sig. $=0,011$ yang berarti $<$ kriteria signifikan $(0,05)$, dan nilai $\mathrm{F}=4502,194$. Maka model persamaan regresi berdasarkan data penelitian adalah signifikan artinya jumlah Penumpang kapal penyeberangan berpengaruh terhadap retribusi pelayanan pelabuhan laut Kota Banda Aceh memiliki nilai pengaruh sebesar $45,02 \%$ dari $100 \%$, sisanya sebanyak $54,98 \%$ dipengaruhi oleh faktor lain.

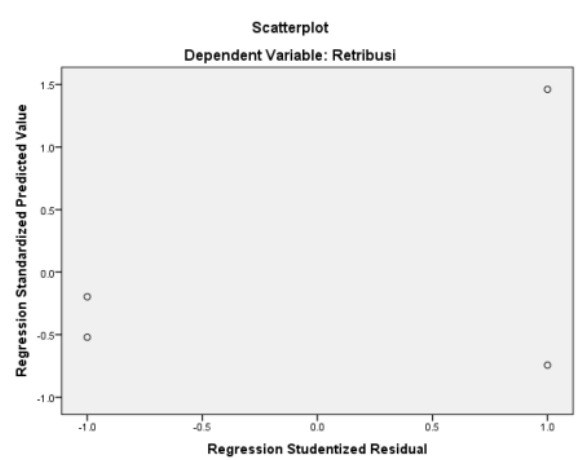

\section{d. Uji Kualitas Data}

1. Uji Asumsi Klasik antara pengaruh jumlah penumpang kapal penyeberangan terhadap retribusi pelayanan pelabuhan dibawah ini menunjukkan bahwa titik-titik data menyebar secara acak tidak membentuk pola tertentu, sehingga dapat disimpulkan tidak terjadi

Gambar 2. Uji Pengaruh Jumlah Penumpang Terhadap Retribusi Pelabuhan

Uji autokorelasi antara pengaruh jumlah wisatawan terhadap pendapatan asli daerah dapat dilihat dari nilai $\mathrm{du}<\mathrm{d}<2$-du dan hasilnya 1,489 $<1,844<2,511$ maka nilai d hitung terletak di daerah tidak ada autokorelasi positif dan negatif, dapat diartikan tidak terjadi autokorelasi. hedeterokesdatisitas.

\begin{tabular}{|c|c|c|c|c|c|}
\hline \multicolumn{6}{|c|}{$\begin{array}{l}\text { Tabel 4. Tabel Durbin-Watson } \\
\text { Model Summary }\end{array}$} \\
\hline Model & $\mathrm{R}$ & R Square & $\begin{array}{l}\text { Adjusted R } \\
\text { Square }\end{array}$ & $\begin{array}{l}\text { Std. Error of the } \\
\text { Estimate }\end{array}$ & Durbin-Watson \\
\hline 1 & $1.000^{\mathrm{a}}$ & 1.000 & 1.000 & 4435984.888 & 1.844 \\
\hline
\end{tabular}

2. Uji Normalitas Data dapat dilakukan dengan menggunakan uji Kolmogorov-Smirnov dengan taraf signifikasi 0,05 (5\%). Dari hasil uji normalitas dibawah ini Terlihat bahwa pada tabel diatas kolom signifikan (Asymp. Sig (2-tailed)) adalah 0,987 atau probabilitas lebih dari 0,05 maka Ho diterima yang berarti populasi berdistribusi normal:

Tabel 5. Tabel Kolmogorov-Smirnov

\begin{tabular}{|c|c|c|}
\hline \multicolumn{3}{|c|}{ One-Sample Kolmogorov-Smirnov Test } \\
\hline & & $\begin{array}{l}\text { Unstandardiz } \\
\text { ed Residual }\end{array}$ \\
\hline $\mathrm{N}$ & & 4 \\
\hline \multirow[t]{2}{*}{ Normal Parameters ${ }^{a, b}$} & Mean &, 0000000 \\
\hline & Std. Deviation & 37022616,23 \\
\hline \multirow[t]{3}{*}{ Most Extreme Differences } & Absolute & 239 \\
\hline & Positive & ,239 \\
\hline & Negative &,- 174 \\
\hline Kolmogorov-Smirnov Z & & .478 \\
\hline Asymp. Sig. (2-tailed) & & 976 \\
\hline
\end{tabular}




\section{c. Uji T}

Hasil uji $\mathrm{T}$ yang dilakukan untk mencari hubungan variabel $\mathrm{X}$ terhadap $\mathrm{Y}$, maka hasil tersebut diuji dengan uji koefisien. Berikut ini hasil uji koefisien :

Tabel 6. Tabel t hitung

Coefficients $^{a}$

\begin{tabular}{|c|c|c|c|c|c|c|}
\hline \multirow{2}{*}{\multicolumn{2}{|c|}{ Model }} & \multicolumn{2}{|c|}{ Unstandardized Coefficients } & \multirow{2}{*}{$\begin{array}{c}\begin{array}{c}\text { Standardized } \\
\text { Coefficients }\end{array} \\
\text { Beta } \\
\end{array}$} & \multirow[b]{2}{*}{$\mathrm{t}$} & \multirow[b]{2}{*}{ Sig. } \\
\hline & & $\mathrm{B}$ & Std. Error & & & \\
\hline \multirow[t]{2}{*}{1} & (Constant) & $-154457193,0$ & 144373953,8 & & $-1,070$ & 397 \\
\hline & JLHPENUMPANG & 3907,963 & 425,912 & ,988 & 9,176 &, 012 \\
\hline
\end{tabular}

a. Dependent Variable: RETRIBUSI

Dari Tabel 6 diperoleh hasil korelasi antara kedua variabel, yang menghasilkan angka 9,176 dengan nilai probabilitas (sig.) 0,012 . Hal ini berarti korelasi antara Jumlah penumpang kapal penyeberangan dan retribusi pelayanan pelabuhan adalah signifikan, karena nilai probabilitas $>0,05$. Sehingga dapat disimpulkan bahwa jumlah penumpang kapal penyeberangan berpengaruh terhadap pendapatan retribusi pelayanan pelabuhan Kota Banda Aceh karena $t$ hitung $9,176>t$ tabel 6,314 .

\section{KESIMPULAN DAN SARAN}

\section{Kesimpulan}

Dari hasil penelitian dan pembahasan penelitian, maka dapat disimpulkan bahwa Jumlah Penumpang Kapal Penyeberangan memiliki pengaruh yang cukup besar terhadap Pendapatan Retribusi Pelayanan Pelabuhan Kota Banda Aceh, hal ini dapat dilihat dari persentasi pengaruh sebesar $45,02 \%$ nilai pengaruh yang dihasilkan dari jumlah penumpang kapal penyeberangan terhadap retribusi pelayanan pelabuhan kota Banda Aceh. Maka semakin banyak penumpang kapal penyeberangan yang berkumpul dipelabuhan Ulee Lheue sebagai pelabuhan satu-satunya dikota Banda Aceh, maka maka akan memberi dampak yang positif bagi penerimaan retribusi pelayanan pelabuhan laut sebagai bagian dari penambahan pendapatan daerah.

\section{Saran}

1. Untuk mempertahankan dan meningkatkan jumlah penerimaan pendapatan retribusi pelayanan pelabuhan laut maka tahun berikutnya kota Banda Aceh perlu meningkatkan sarana dan prasarana pelabuhan Ulee Lheue, sehingga akan memperbesar pendapatan asli daerah yang dapat meningkatkan anggaran pembangunan daerah.

2. Pemerintah Kota Banda Aceh perlu meningkatkan kerja sama dengan masyarakat sekitar menjaga fasilitas dan kelestarian pelabuhan dengan cara menjaga kebersihan wilayah pelabuhan sekitarnya agar pengunjung lebih nyaman berada disekitar pelabuhan tersebut serta meningkatkan keamanan agar pengunjung merasa aman. 
Jurnal Humaniora, 1(2), 99-108

Oktober 2017

http://jurnal.abulyatama.ac.id/humaniora

\section{DAFTAR PUSTAKA}

Badan Perencanaan Pembangunan Daerah Kota Banda Aceh (2016). Statistik Banda Aceh 2013-2016. Banda Aceh: Pemerintah Kota Banda Aceh.

Badan Pusat Statistik Provinsi Aceh. (2016). Statistik Daerah Provinsi Aceh 2032016. Banda Aceh: Pemerintah Aceh. Oktaparizki, Rio. (2016). Persepsi Pengguna seta Faktor-faktor Pengembangan Sarana dan Prasarana Pelabuhan Penyeberangan Ulee Lheue. Fakultas Teknik Sipil Universitas Syiah Kuala.

Sugiyono. (2008). Metode Penelitian Kuantitatif, Kualitatif dan $R \& D$. Bandung: Alfabeta.

Sugiyono. (2011). Statistika Untuk Penelitian. Bandung: Alfabeta. 